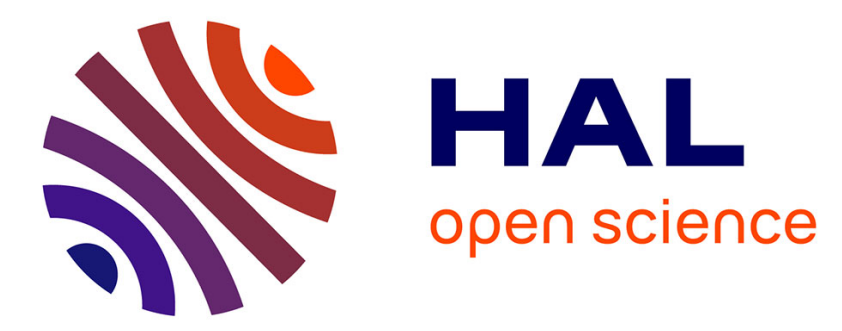

\title{
Sandwich-structured TiO 2 inverse opal circulates slow photons for tremendous improvement in solar energy conversion efficiency
}

Ehsan Eftekhari, Pierre Broisson, Nikhil Aravindakshan, Zhiqing Wu, Ivan S Cole, Xiaomin Li, Dongyuan Zhao, Qin Li

\section{To cite this version:}

Ehsan Eftekhari, Pierre Broisson, Nikhil Aravindakshan, Zhiqing Wu, Ivan S Cole, et al.. Sandwichstructured TiO 2 inverse opal circulates slow photons for tremendous improvement in solar energy conversion efficiency. Journal of Materials Chemistry A, 2017, 5 (25), pp.12803-12810. 10.1039/C7TA01703K . hal-01624558

HAL Id: hal-01624558

https://hal-univ-rennes1.archives-ouvertes.fr/hal-01624558

Submitted on 26 Oct 2017

HAL is a multi-disciplinary open access archive for the deposit and dissemination of scientific research documents, whether they are published or not. The documents may come from teaching and research institutions in France or abroad, or from public or private research centers.
L'archive ouverte pluridisciplinaire HAL, est destinée au dépôt et à la diffusion de documents scientifiques de niveau recherche, publiés ou non, émanant des établissements d'enseignement et de recherche français ou étrangers, des laboratoires publics ou privés. 


\title{
Sandwich-Structured $\mathrm{TiO}_{2}$ Inverse Opal Circulates Slow Photons for Tremendous Improvement in Solar Energy Conversion Efficiency
}

\author{
Ehsan Eftekhari, ${ }^{a}$ Pierre Broisson, ${ }^{b}$ Nikhil A, ${ }^{a}$ Zhiqing Wu, ${ }^{a}$ Ivan S. Cole, ${ }^{c}$ Xiaomin Li, ${ }^{\text {a,d }}$ Dongyuan \\ Zhao, ${ }^{\mathrm{d}, \mathrm{e}}$ and Qin Li ${ }^{{ }^{\mathrm{a}}}$ \\ Photon management has enabled a true revolution in the development of high-performance semiconductor materials and \\ devices. Harnessing the highest amount of energy from photon relies on an ability to design and fashion structures to trap \\ the light for the longer time inside the device for more electron excitation. The light harvesting efficiency in many thin-film \\ optoelectronic devices is limited due to low photon absorbance. Here we demonstrate for the first time that slow photon \\ circulation in sandwich-structured photonic crystals with two stopbands fine tuned are ideally suited to enhance and \\ spectrally engineer light absorption. The sandwich-structured $\mathrm{TiO}_{2}$ inverse opal possesses two stopbands, whose blue or \\ red edge is respectively tuned to overlap with $\mathrm{TiO}_{2}$ electronic excitation energy, thereby circulating the slow photons in the \\ middle layer and enhancing light scattering at layer interfaces. This concept, together with the significantly increased \\ control over photon management opens up tremendous opportunities for the realization of a wide range of high- \\ performance, optoelectronic devices, and photochemical reactions.
}

\section{Introduction}

Advanced photon management is essential for the next generation of photoenergy conversion devices. One of the critical bottlenecks for efficiency improvement of photoactive semiconductor is low absorbance of light. ${ }^{1,} 2$ Significant research efforts have been made to enhance photon collection by extending absorption width through chemical doping ${ }^{3-5}$ and increasing the path length of light by scattering and/or resonance., 7 In the past decade, photonic crystal (PC) structures have received increased attention for enhancing photochemical energy conversion by intensifying light-matter interactions without chemical modification., ${ }^{1,8}$

With periodic modulation of the refractive index, PC possesses a stopband which forbids light of certain frequencies from propagation at certain crystallographic direction. ${ }^{10,} 11$ Since most of the $\mathrm{TiO}_{2} \mathrm{PCs}$ are fabricated through colloidal selfassembly followed by structural inversion, they are also called inverse opals (IOs). ${ }^{12}$ IOs can enhance light harvesting efficiency by multiple mechanisms: firstly, the open macroporous structure of the $\mathrm{TiO}_{2}$ IO allows the light to penetrate deep into the film. ${ }^{13,}{ }^{14}$ Secondly, the uniform macroporous structure improves mass transport and reduces electron-hole recombination rate. ${ }^{15-17}$ More importantly, at the edge of photonic bandgaps, the group velocity of the light is significantly slowed down, becoming anomalously small, owing to the effect of nonlinear dispersion, creating "slow photons"; when the energy of slow photons is in resonance with the absorption edge of the material which is usually of low absorbance, the photon absorption can be enhanced. ${ }^{18-20}$ By matching the red or blue edge of photonic stopbands with the electronic excitation energy of the material, more than 2 fold enhancement of photocatalytic efficiency of $\mathrm{TiO}_{2}$ has been demonstrated. ${ }^{21-26}$ But, have we reached the limit of PC's amplification function in photochemistry? Can the effective optical path length of the 'slow photons' be further extended? So far, in all reported work, only monolithic $\mathrm{TiO}_{2}$ inverse opals $\left(\mathrm{M}-\mathrm{IO}-\mathrm{TiO}_{2}\right)$ have been studied for generating slow photons that can amplify photochemistry; the potential of photon management using novel architectures implementing photonic properties is yet to be explored. ${ }^{2,27}$

Here, we demonstrate the possibility of engineering photon circulation inside semiconductor inverse opal photonic crystals for tremendous enhancement of light absorption for device applications. To illustrate this concept and its importance, we design and investigate the photon management in a sandwichstructured $\mathrm{TiO}_{2}$ inverse opal photonic crystals configuration through a measurement of their photocatalytic activity. Such sandwich configuration can be viewed as an unconventional Fabry-Pérot microcavity resonator that can trap light between the top and bottom PC layers. We demonstrate an additional four-fold gain of photochemistry efficiency in comparison to the monolithic inverse opal by utilizing the sandwichstructured configuration.

The sandwich structure is comprised of a top and a bottom $\mathrm{PC}$ layer with stopband's red edge overlapping with the $\mathrm{TiO}_{2}$ electronic excitation energy at $380 \mathrm{~nm}$ (see Supporting Information Fig. S1), and a middle PC layer with stopband blue edge overlapping with $\mathrm{TiO}_{2}$ excitation energy, as illustrated in Fig. 1a. We name this configuration sandwich-structured $\mathrm{TiO}_{2}$ inverse opal $\left(\mathrm{S}-\mathrm{IO}-\mathrm{TiO}_{2}\right) .^{\ddagger}$ Based on whether it is the red or blue edge of the stopband overlapping with the $\mathrm{TiO}_{2}$ excitation energy, the PC layer is denoted as R or B layer, respectively (Fig. S2). In this new structural design, an unconventional Fabry-Pérot microcavity resonator has been formed, which could circulate the light rejected by the top and bottom PCs (stopband centring at $340 \mathrm{~nm}$ ) that partially overlaps with the middle layer B's stopband blue edge as shown in Fig. 1c. It should be noted that the 'mirrors' in this Fabry-Pérot microcavity are colloidal PCs that generate slow photons which are confined in the low refractive index phase, namely air spheres. ${ }^{22}$ In addition, the cavity itself is another PC with a 
different lattice constant, which could further slowdown the slow photons by circulating them in the middle layer PC, since the slow photon energy coincides with the blue edge of middle layer PC's stopband. Such a sandwich-structured PC design has much-increased light trapping effect, which can give rise to the extraordinary light absorbance of the $\mathrm{TiO}_{2}$ without adding metallic materials such as gold, silver, aluminium and graphene or CdS Inverse Opals. ${ }^{28-32}$ Moreover, we also observed an extended electron-hole lifetime in $\mathrm{TiO}_{2}$ entirely owing to the light manipulation in $\mathrm{S}-\mathrm{IO}-\mathrm{TiO}_{2}$.

\section{Experimental}

\section{Fabrication of inverse opal films}

Polystyrene (PS) spheres with the size of $175 \pm 5 \mathrm{~nm}$ and $230 \pm 5$ $\mathrm{nm}$ were synthesized by an emulsifier-free emulsion polymerization method as per the earlier report. ${ }^{33,34}$ PS opals films with different configurations were fabricated on $2 \times 2 \mathrm{~cm}$ substrates. All substrates (FTO and glass) were cleaned by acetone, DI water, and ethanol in an ultrasonic bath for 15 min. Then immersed in piranha solution (a solution of sulphuric acid and hydrogen peroxide, 70:30vol \%). (WARNING! piranha solution reacts violently with organic materials. Handle with caution). All substrates were washed with copious DI water and dried under nitrogen gas.

Monolithic configuration: monolithic opal films were obtained by deposition of $175 \pm 5 \mathrm{~nm}$ and $230 \pm 5 \mathrm{~nm}$ PS spheres by horizontal deposition method. ${ }^{35}$

Heterostructure configuration: heterostructure film was
Table 1 The polystyrene (PS) particle diameters, air holes diameter, crystalline grain sizes, calculated and experimental stopbands.

\begin{tabular}{cccccc}
\hline sample & $\begin{array}{c}\text { Ps diameter } \\
(\mathrm{nm})\end{array}$ & $\begin{array}{c}\text { Air diameter } \\
(\mathrm{nm})\end{array}$ & $\begin{array}{c}\text { Crystalline } \\
\text { size }(\mathrm{nm})\end{array}$ & $\begin{array}{c}\text { calculated } \\
\text { stopband }(\mathrm{nm})\end{array}$ & $\begin{array}{c}\text { Experimental } \\
\text { stopband }(\mathrm{nm})\end{array}$ \\
\hline $\mathrm{R}$ & $175 \pm 5$ & $140 \pm 5$ & $5-20 \pm 2$ & 340 & 346 \\
$\mathrm{~B}$ & $230 \pm 5$ & $180 \pm 5$ & $5-20 \pm 2$ & 430 & 432 \\
\hline
\end{tabular}

obtained by horizontal deposition of $175 \pm 5 \mathrm{~nm}$ PS sphere followed by deposition of $230 \pm 5 \mathrm{~nm}$ by doctor blading method on top of the first monolithic film.

Sandwich-structured configuration: the sandwich-structured film was obtained by horizontal deposition of $175 \pm 5 \mathrm{~nm}$ PS sphere (bottom film) followed by deposition of $230 \pm 5 \mathrm{~nm}$ PS spheres as a middle film and $175 \pm 5 \mathrm{~nm}$ PS sphere as a top film by doctor blading method. A Bragg diffraction model ${ }^{36}$ predicts that a partial stopband occurs. at. . $^{37}$

$$
\lambda_{\max }=1.629 \cdot D \cdot \sqrt{n_{e f f}^{2}-\sin ^{2} \theta}
$$

where $\lambda$ is the stopband wavelength, $D$ is the diameter of air hole, and $n_{\text {eff }}$ is the effective refractive index of the materials, $\theta$ is the angle between the incident light and the lattice planes. The latter is estimated by:

$$
n_{\text {efi }}=\varphi n_{\text {gold }}+(1-\varphi) n_{\text {rotd }}
$$

with solid $\left(\mathrm{TiO}_{2}\right)$ volume fractions $(\varphi)$ of 0.15 (calculated from the inverse opal stopband spectra data), the refractive index of anatase being $=2.5$ for $\mathrm{TiO}_{2}$ and $=1.33$ for water (filled by water) at $\theta=0^{\circ}$. We, therefore, synthesized PS colloids of 175

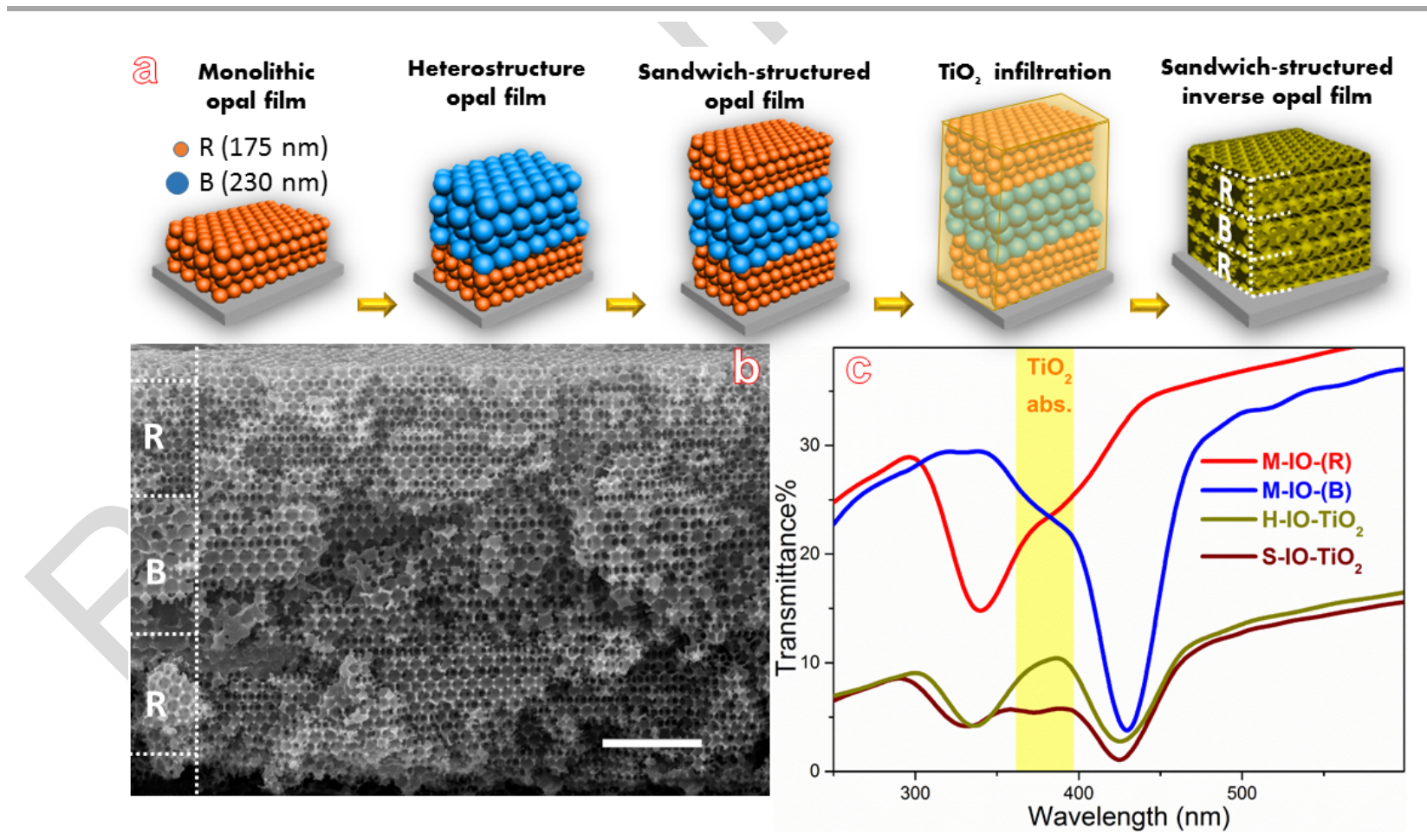

Fig. 1 (a) Schematic of fabrication procedure for sandwich-structured $\mathrm{TiO}_{2}$ inverse opal $\left(\mathrm{S}-\mathrm{IO}-\mathrm{TiO}_{2}\right)$. (b) Cross-sectional SEM image of S-IO-TiO ${ }_{2}$, the scale bar is $1 \mu \mathrm{m}$. (c) UV-vis transmission of monolithic (R and B), heterostructure and sandwich-structured inverse opal films in water. The shaded region indicates the electronic absorption band of $\mathrm{TiO}_{2}$. 
$\pm 5 \mathrm{~nm}$ and $230 \pm 5 \mathrm{~nm}$ in size, which formed air holes with diameters of $140 \pm 5 \mathrm{~nm}$ and $180 \pm 5 \mathrm{~nm}$, respectively, after calcination at $450^{\circ} \mathrm{C}$ for $4 \mathrm{hrs}$. Shrinkage of photonic opal structure during calcination is unavoidable, the air spheres were decreased in size to approximately $75 \%$ of the original polystyrene sphere.

Fabrication of $\mathrm{TiO}_{2}$ Inverse Opals: The precursor was first prepared by mixing $50 \mu \mathrm{L}$ of Titanium(IV) butoxide in the 10.0 $\mathrm{mL}$ anhydrous ethanol then stirred for 5 minutes for a full dispersion of Titanium(IV) butoxide. $100 \mu \mathrm{L}$ of the precursor was carefully dropped in the middle of all opal films. The infiltration process was repeated three times in order to increase the filling of the voids. All films were first dried at 60 ${ }^{\circ} \mathrm{C}$ for $4 \mathrm{~h}$ then calcined at $450{ }^{\circ} \mathrm{C}$ with a ramp rate of $1{ }^{\circ} \mathrm{C} \mathrm{min}$

${ }^{1}$. After $4 \mathrm{hrs}$, monolithic inverse opal films with the air holes diameter of $140 \pm 5 \mathrm{~nm}$ for M-IO-R, and $180 \pm 5 \mathrm{~nm}$ for M-IO-B, as well as heterostructure inverse opal film $\left(\mathrm{H}-\mathrm{IO}-\mathrm{TiO}_{2}\right)$ and sandwich-structured inverse opal film $\left(\mathrm{S}-\mathrm{IO}-\mathrm{TiO}_{2}\right)$, were obtained. The nanocrystal $\mathrm{TiO}_{2}\left(\mathrm{nc}-\mathrm{TiO}_{2}\right)$ film was prepared by dropping the $100 \mu \mathrm{L}$ titanium Titanium(IV) butoxide solution on the substrate for three times followed by the same calculation procedure described above.

\section{Photocatalytic activity measurement}

The photocatalytic activities of the inverse opal films and nc$\mathrm{TiO}_{2}$ film were evaluated by two methods: photodegradation of a model pollutant Rhodamine $B$ (RhB) and photoelectrochemical (PEC) water splitting.

The photodegradation of dye was carried out by placing films on the film holder at the bottom of a beaker filled with $10 \mathrm{~mL}$ RhB aqueous solution of $0.01 \mathrm{mM}$ in the dark to allow the RhB to be adsorbed onto the film surface. After the adsorption reached the equilibrium, the light was turned on to start the photodegradation experiment. ${ }^{38}$ The photocatalytic degradation of the $\mathrm{RhB}$ on $\mathrm{nc}-\mathrm{TiO}_{2}$, monolithic, heterostructure, and sandwich-structured $\mathrm{TiO}_{2}$ inverse opals initiated and conducted under irradiation from a $300 \mathrm{~W}$ Xe lamp (PLS-SXE300, Perfect Light) with the light intensity of 150 $\mathrm{mWcm}^{-2}$. At every $5 \mathrm{~min}$ interval, a solution of $1 \mathrm{~mL}$ was taken out for absorption measurement. After every analysis, the analysed liquid was quickly poured back into the beaker to ensure a roughly equivalent volume of solution. The absorption spectrum of the solution was then recorded with Agilent 8453 UV-Vis spectrometer.

The photodegradation efficiency $(\varnothing)$ of the films were calculated from the following elililiation: ${ }^{39}$

$$
\otimes=\left(E_{0}-\epsilon_{t}\right) \underset{C_{0}}{ } \times 100 \%
$$

where $C_{0}$ and $C_{t}$ are the absorbance values at time zero and time $t$, respectively. The kinetics of the degradation reaction was also calculated by usir ${ }_{t}$ the following equation: ${ }^{40}$

$$
\ln \overline{C_{0}}=-k t
$$

where $k$ is the rate constant of the photocatalytic degradation reaction.
The photoelectrochemical (PEC) measurements were obtained by preparing $\mathrm{nc}-\mathrm{TiO}_{2}$ and inverse opal photoanodes as working electrodes, a platinum wire as a counter electrode and $\mathrm{Ag} / \mathrm{AgCl}$ as a reference electrode, respectively, in a $0.1 \mathrm{M} \mathrm{Na}_{2} \mathrm{SO}_{4}$ electrolyte deaerated by purging $\mathrm{N}_{2}$ gas into the electrolyte. ${ }^{41}$,

${ }^{42}$ For the photodegradation evaluation, all inverse opal and nc- $\mathrm{TiO}_{2}$ films were fabricated on glass quartz substrate while for photoelectrochemical water splitting all films were fabricated on FTO ( $7 \Omega / \mathrm{sq})$ substrate. In both PEC and photodegradation experiments, the film was placed in the cell at the normal angle to the light source. The IPCE has been calculated with the formula as follohir $t^{3}$

$$
I P^{2} C E=\frac{h r t}{\lambda P}
$$

where $h$ and $c$ represent Planck's constant and the speed of light in a vacuum, respectively. $I$ is the photocurrent density $\left(\mathrm{mAcm}^{-2}\right), P$ is intensity $\left(\mathrm{mWcm}^{-2}\right)$ and $\lambda$ is the wavelength (nm) of the incident monochromatic light.

The transient decay time can be calctotated by: ${ }^{44}$

$$
\ln D=\frac{-}{t}
$$

where $t$ is the time and $\tau$ is the transient time constant which is the time at $\ln D=-1$. The transient decay time can be found from a logarithmic plot of parameter $D$, given by the equation: ${ }^{45}$

$$
D=\frac{I_{t}-I_{g}}{I_{m}-I_{s}}
$$

where $I_{t}$ is the photocurrent at time $t$.

\section{Simulation Section}

The theoretical simulation of the photon field intensity and plane wave expansion method inside the sandwich-structured inverse opal was simulated with the finite-difference-timedomain by using Optiwave OptiFDTD $7 .^{46,47}$ In order to save computer memory and increase simulation speed, the 64-bit simulator has been chosen for computational simulation. OptiFDTD makes a few more assumptions that allow Maxwell's expressions to be simplified even further, and fully capable of solving problems in three dimensions. The sample was designed and simulated in three dimensions (3D) to model the propagation of light through the photonic crystal.

Based on 3D FDTD analysis simulations, we quantify slow photon circulation with respect to monolithic, heterostructure and sandwich-structured of equivalent experimental parameters. By utilizing the scalability of samples configurations, we choose the feature thickness of the simulated structures bigger than the as-fabricated structures for the purpose of better observation of slow photon circulation. A cubic box is chosen as the calculation boundary. This cubic box meshes in the space domain, the space steps are $D_{x}, D_{y}$, and $D_{z}$ in $\mathrm{x}, \mathrm{y}$, and $\mathrm{z}$ directions respectively. ${ }^{46} \mathrm{In}$ order to calculate a broad wavelength range excitation source, a Gaussian-distributed pulsed light source is used. Its mathematical exp [res 1 igntcantbe off $^{2}$ itten as:

$T(t)=\exp \left[-\frac{1}{2}\left(\frac{t_{w}}{t_{w}}\right) \sin (w t)\right]$ 
where $t_{\text {off }}$ is the offset time, $t_{w}$ is the half width of the pulse, and $w$ is the central frequency of the excitation light. The excitation light incidence angle was taken equal to $0^{\circ}$ to the sample. The input field is the element to define the incident light. Observation point is used to record the data like electric or magnetic field at the desired point.

For the structure parameters, the solid volume fraction is taken as 0.15 , as determined from experiments. Immersion of the film in water with refractive index (RI) of 1.33 is assumed. The inverse opal crystal with FCC lattice is assumed to be oriented such that the (111) crystallographic direction. Cladding and substrate layer are set to be $0.5 \mu \mathrm{m}$ with the materials both set as air (RI:1). In the Atom Waveguides in Unit Cell box, Titania was chosen for the material (RI: 2.5), and radius of $0.140 \mu \mathrm{m}$ for the top and bottom layers and 0.180 $\mu \mathrm{m}$ for the middle layer.

\section{Characterization}

Topographic characterizations were performed using a scanning electron microscope (SEM) using a JEOL 7001, operating at $15 \mathrm{KV}$ and a transmission electron microscope (TEM) using FEI Tecnai F30. Elements mapping of the film was studied by using an energy-dispersive X-ray analyser backscattered electron (BSE-EDX). The compositions of the films were characterized by X-ray diffraction (XRD) using a Bruker D8 Advance with CuKa1 radiation $(\lambda=1.5418 \AA \AA$ ). Transmission spectra were measured on an Agilent 8453 UV-Vis spectrometer. The photocurrent measurement was carried out on a Pine Instrument Wave Nano Potentiostat controlled by a computer running Aftermath software. The light emitted from a PLS-SXE-300UVligth source.

\section{Results and discussion}

The fabrication method for this $\mathrm{S}-\mathrm{IO}-\mathrm{TiO}_{2}$ is facile as illustrated in Fig. 1a; the trilayer colloidal PC films were self-assembled by the horizontal deposition method of polystyrene (PS) spheres in sequence. ${ }^{48}$ After the R-B-R trilayer colloidal template was fabricated, the $\mathrm{TiO}_{2}$ precursor, namely Titanium(IV) butoxide in ethanol, was infiltrated, which was subsequently calcined at $450{ }^{\circ} \mathrm{C}$ for $4 \mathrm{~h}$, forming 10 fashioned from anatase nanocrystals (Fig. S3 and Fig. S4). The spherical diameters of the colloidal crystal polystyrene templates, namely $175 \pm 5 \mathrm{~nm}$ for the $\mathrm{R}$ layers and $230 \pm 5 \mathrm{~nm}$ for the $B$ layer, the resultant air spheres in the $\mathrm{TiO}_{2}$ inverse opals, namely $140 \pm 5 \mathrm{~nm}$ for the R layers and $180 \pm 5 \mathrm{~nm}$ for the $B$ layer, and their stopband positions are enlisted in Table 1. The size selection of colloidal particle is based on the following design rationale: the top and bottom layers of IOs have the red edge of its stopband overlapping

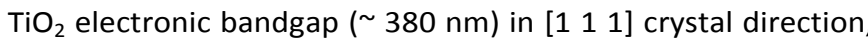

therefore stopband peaks at about $340 \mathrm{~nm}$; while the middle layer 10 possesses a stopband whose blue edge overlaps the $\mathrm{TiO}_{2}$ bandgap, therefore the stopband peaks at around 420 $\mathrm{nm}$, as shown in Fig. 1c. Fig. $1 \mathrm{~b}$ presents the cross-sectional $\mathrm{SEM}$ image of the S-IO- $\mathrm{TiO}_{2}$. Although the three layers R/B/R are distinguishable due to the difference in sphere size, there are no discernible spatial gaps between layers, because only one inversion step was applied after the $R / B / R$ trilayer template was formed.

It is known, that when PCs of different bandgaps are stacked together, the resultant multilayer structure retains all individual stopbands. ${ }^{49}$ By creating heterostructured $\mathrm{TiO}_{2}$ inverse opal $\left(\mathrm{H}-\mathrm{IO}-\mathrm{TiO}_{2}\right)$ which has bottom layer's stopband red edge and top layer's stopband blue edge overlapping $\mathrm{TiO}_{2}$ electronic excitation energy, respectively, we can observe two stopbands on the UV-vis spectrum as shown in Fig. 1c.

In comparison to the monolithic counterparts of same thickness (M-IO-R and $\mathrm{M}-\mathrm{IO}-\mathrm{B}$ ), the transmission of $\mathrm{H}-\mathrm{IO}-\mathrm{TiO}_{2}$ throughout the spectrum is significantly reduced by approximately $15-20 \%$, likely due to much increased light scattering at the interface between the two PC layers of different lattice parameters because of the drastic change of group velocity at the interface. The $\mathrm{S}-\mathrm{IO}-\mathrm{TiO}_{2}$ of the same thickness shown in Fig. $1 \mathrm{~b}$ also possesses two stopbands with similar transmission capacity, but an additional $5 \%$ reduction in transmission can be observed between two stopbands coinciding with $\mathrm{TiO}_{2}$ bandgap edge (marked by yellow shade), compared to that of $\mathrm{H}-\mathrm{IO}-\mathrm{TiO}_{2}$. Together with the broadening of both stopbands, it suggests that the photon energy between two stopbands is well coupled in the S-IO- $\mathrm{TiO}_{2}$ structure.

The photocatalytic efficiency of the $\mathrm{S}-\mathrm{IO}_{-} \mathrm{TiO}_{2}$ was demonstrated by hydrogen production via water splitting under white light normal direction irradiation measured by the current magnitude, in comparison to that of the $R$ and $B$ monolithic IO films (M-IO-R, M-IO-B), and the heterostructure $\mathrm{H}-\mathrm{IO}-\mathrm{TiO}_{2}(\mathrm{R} / \mathrm{B})$, as well as sandwich structure of $\mathrm{B}-\mathrm{R}-\mathrm{B}$ as shown in Fig. S5. As shown in Fig. 2a, all 10 photoanodes generated significantly higher photocurrent than the nanocrystalline $\mathrm{TiO}_{2}$ film $\left(\mathrm{nc}-\mathrm{TiO}_{2}\right)$ of the same thickness. The magnitude of the photocurrent can be ranked as $I_{\text {S-IO-TiO2 }}>I_{\text {H-IO- }}$ ${ }_{\text {TiO2 }}>I_{M-I O-B}>I_{M-I O-R}>I_{n C-T i O 2}$. An order of magnitude difference in photocurrent density between the inverse opal $\mathrm{TiO}_{2}$ and nc$\mathrm{TiO}_{2}$ is owing to the open macroporous structure, which increases the contact surface area between photoanode and electrolyte and better light penetration, ${ }^{50,51}$ as well as the slow photon effect. $^{52}$ Therefore, to understand the effect of sandwich-structure and heterostructure, our comparison baseline is the monolithic $\mathrm{TiO}_{2} \mathrm{IO}$, specifically M-IO-B. 

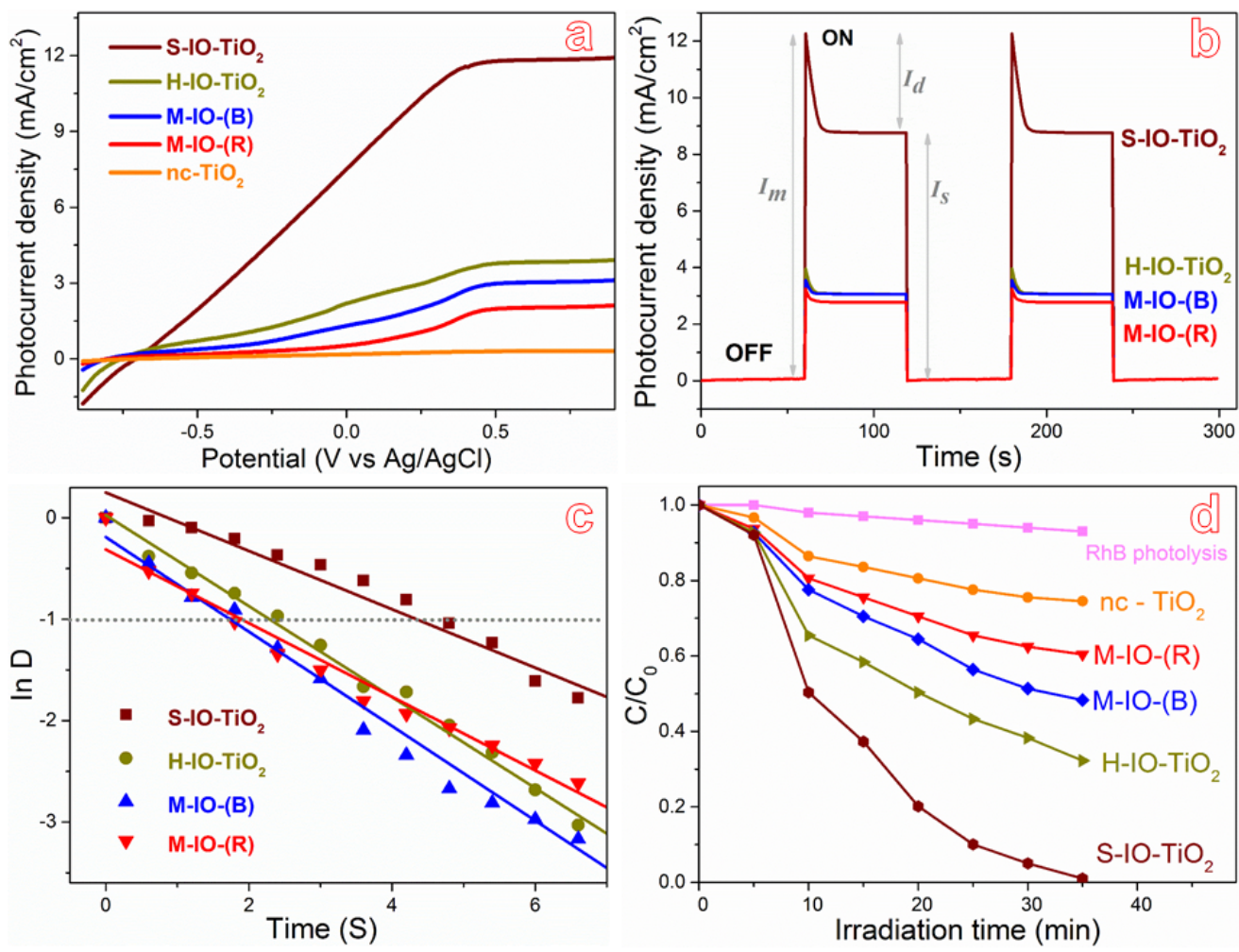

Fig. 2 (a) $I-V$ curves of the inverse opal and nc- $\mathrm{TiO}_{2}$ films under UV-visible light illumination. (b) $I-t$ curves of the inverse opal films at a bias of $+0.5 \mathrm{~V}$ under UV-visible illumination. (c) Transient decay times of the inverse opal photoanodes (see details in the equation 6 for the definition of parameter D). (d) Photodegradation of concentration change of RhB versus irradiation time in the presence of inverse opal films from 0 to 5 min in dark and after 5 min under

The observation of M-IO-B performing better than M-IO-R under white light irradiation is consistent with previous observations. $^{22,37}$ When the red edge of the stopband coincides with the electronic bandgap of $\mathrm{TiO}_{2}$ (M-IO-R), although the slow photons concentrate in the high dielectric medium, namely the $\mathrm{TiO}_{2}$ skeleton, the fact that the stopband rejects a considerable amount of light centred at $340 \mathrm{~nm}$ reduces the overall usage of light. The $10 \%$ increase in photocurrent generated by $\mathrm{H}-\mathrm{IO}-\mathrm{TiO}_{2}$ in comparison to $\mathrm{M}-\mathrm{IO}-\mathrm{B}$ can be explained by the scattering effect at the interface, consistent with transmission measurement displayed in Fig. 1c showing an overall enhanced light absorbance. Prominently, a 5 -fold enhancement in photocurrent density was achieved by $\mathrm{S}-\mathrm{IO}-\mathrm{TiO}_{2}$ in comparison to that of $\mathrm{M}-\mathrm{IO}-(\mathrm{B})$, markedly higher than those reported elsewhere. ${ }^{14,53-57}$ The calculated photonto-electron conversion efficiency (IPCE) at the wavelength (380 $\mathrm{nm}$ ) of the $\mathrm{S}-\mathrm{IO}-\mathrm{TiO}_{2}$ photoanodes reached a value of $53 \%$, significantly higher than that of $\mathrm{H}-\mathrm{IO}-\mathrm{TiO}_{2}, \mathrm{M}-\mathrm{IO}-(\mathrm{B})$ and nc$\mathrm{TiO}_{2}(15 \%, 10 \%$, and $1 \%$, respectively). Such an extraordinary performance of $\mathrm{S}-\mathrm{IO}-\mathrm{TiO}_{2}$ demonstrates that the light utilization at $380 \mathrm{~nm}$ has been enhanced by more than 5 fold, in comparison to $\mathrm{M}-\mathrm{IO}-\mathrm{B}$.

It is worth mentioning that in sandwich-structured $\mathrm{CPhC}$ configurations, the R-B-R configuration performs better than B-R-B, as shown in Fig. S5. This is because the contribution of the middle layer to light absorption is predominantly due to light circulation. In the R-B-R configuration, it is the high energy (>3.2 eV) light that is circulated in the middle layer, which can be effectively absorbed by the $\mathrm{TiO}_{2}$; whereas in the $\mathrm{B}-\mathrm{R}-\mathrm{B}$ configuration, the circulating light is of lower energy (centred around $420 \mathrm{~nm}$ ), therefore the circulating light is not absorbed by $\mathrm{TiO}_{2}$ as effectively as in R-B-R structure.

We further studied the PC structures on electron-hole recombination time. Fig. $2 \mathrm{~b}$ shows the photocurrent response over time ( $I-t$ curves) of the monolithic, heterostructured and sandwich-structured films measured at $+0.5 \mathrm{~V}$ with chopped illumination at a rate of $60 \mathrm{~s}$ exposure followed by $60 \mathrm{~s}$ nonillumination. The sharp spike in the photocurrent during the on/off illumination cycles indicates fast generation and recombine of photogenerated electrons from the inverse opal films to the current collector. $^{58}$ By performing the transient

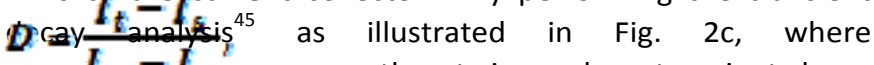
$I_{m}-I_{\mathrm{g}} \quad$ a more than twice as long transient decay time of $4.8 \mathrm{~s}$ is observed for the $\mathrm{S}-\mathrm{IO}-\mathrm{TiO}_{2}$ in comparison to 2.6, 2 and $1.8 \mathrm{~s}$ for $\mathrm{H}-\mathrm{IO}-(\mathrm{R} / \mathrm{B}), \mathrm{M}-\mathrm{IO}-(\mathrm{B})$ and $\mathrm{M}-\mathrm{IO}-(\mathrm{R})$, respectively. Since all the other parameters such as porosity, $\mathrm{TiO}_{2}$ crystal quality are identical among the IOs, it is the light management in the $\mathrm{S}-\mathrm{IO}-\mathrm{TiO}_{2}(\mathrm{R} / \mathrm{B} / \mathrm{R})$ that gives rise to the slow-down of electron-hole recombination.

The photocatalytic reactivity of $S-1 \mathrm{O}-\mathrm{TiO}_{2}(\mathrm{R} / \mathrm{B} / \mathrm{R})$ was further tested by a series of photodegradation of Rhodamine $B$ dye molecules (RhB) in aqueous solution. As shown in Fig. $2 \mathrm{~d}$, the reactivity of all the as-prepared films followed the same order as in the photoelectrochemical reaction, namely S-IO- 

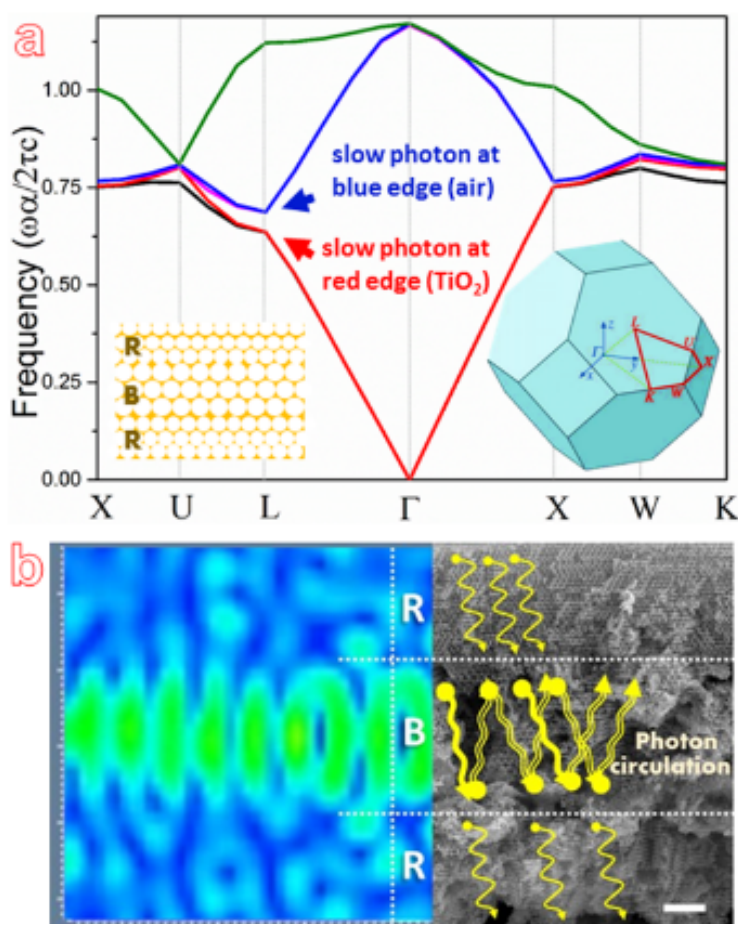

Fig. 3 (a) Band diagram calculated by plane-wave expansion of sandwichstructured inverse opal. (b) The cross-sectional SEM image and patterns of the simulated electric field for $\mathrm{S}-\mathrm{IO}-\mathrm{TiO}_{2}$, simulated through the FDTD

$\mathrm{TiO}_{2}>\mathrm{H}-\mathrm{IO}-\mathrm{TiO}_{2}>\mathrm{M}-\mathrm{IO}-(\mathrm{B})>\mathrm{M}-\mathrm{IO}-(\mathrm{R})>\mathrm{nc}-\mathrm{TiO}_{2}$. After only 35 min of UV-vis light irradiation in the normal direction, $99 \%$ of $\mathrm{RhB}$ was degraded by $\mathrm{S}-\mathrm{IO}-\mathrm{TiO}_{2}$, whilst only $39 \%$ was degraded by $\mathrm{M}-\mathrm{IO}-\mathrm{B}$. The kinetics of the degradation reactions follow the first-order exponential decay and the rate constants $(\mathrm{k})$ were calculated as $0.0088,0.0205,0.0211$ and $0.1317 \mathrm{mni}^{-1}$ for nc- $\mathrm{TiO}_{2}, \mathrm{M}-\mathrm{IO}-(\mathrm{B}), \mathrm{H}-\mathrm{IO}-\mathrm{TiO}_{2}$ and S-IO-TiO 2 , respectively.

To compare quantitatively on the photodegradation efficiency, an enhancement factor (EF) of 6.4, calculated as the ratio of the decay rate constant of $\mathrm{S}-\mathrm{IO}-\mathrm{TiO}_{2}$ to $\mathrm{M}-\mathrm{IO}-(\mathrm{B})$, was obtained; whilst an EF of 2.3 was obtained for $\mathrm{M}-\mathrm{IO}-(\mathrm{B})$ to nc$\mathrm{TiO}_{2}$, which is consistent with Chen et. $\mathrm{al}^{22}$ It is important to note that the efficiency enhancement from $\mathrm{M}-\mathrm{IO}-(\mathrm{B})$ to sandwich-structure is far greater than that the ratio between $\mathrm{M}-\mathrm{IO}-(\mathrm{B})$ and $\mathrm{nc}-\mathrm{TiO}_{2}$. It's also worth noting that in the transmission spectra presented in Fig. 1C, the difference in transmission between $\mathrm{H}-\mathrm{IO}-\mathrm{TiO}_{2}$ and $\mathrm{S}-\mathrm{IO}-\mathrm{TiO}_{2}$ is relatively small, however, their photochemistry efficiency is markedly different.

Why could $\mathrm{S}-\mathrm{IO}-\mathrm{TiO}_{2}$ be so effective in utilizing the light in comparison to its monolithic and heterostructure counterparts? We performed theoretical simulation based on Plane Wave Expansion method using Optiwave OptiFDTD 7. Fig. 3a presents the photonic band diagram of close-packed $\mathrm{TiO}_{2}$ sandwich-structured inverse opal with water filling the voids; it shows a pseudo stopband at the $L$ point of the irreducible Brillouin zone along the $\Gamma L$ (111) direction. ${ }^{59} \mathrm{~A}$ comparison with the photonic band diagrams of monolithic, and heterostructure (Fig. S6) shows that the bandgap depth of sandwich-structured increases and its edges have moved to higher normalized frequencies $(\alpha \omega / 2 \pi c)$. As shown in Fig. S7, the group velocity of slow photons, which can be approximated by the slope at band edges, ${ }^{27}$ is decreased from monolithic to sandwich-structure. The light propagation inside the $\mathrm{S}-\mathrm{IO}-\mathrm{TiO}_{2}$ is revealed by the simulations of the electromagnetic fields inside the inverse opals. The tomography of the field intensity shown in Fig. 3b manifests the high-intensity field of the absorption light in the middle PC layer of the $\mathrm{S}-\mathrm{IO}-\mathrm{TiO}_{2}$; Light is trapped in the middle layer and bounces between the top and bottom layers, creating a photon circulation effect. It is also observable that in the top and bottom PC layers, the light is more concentrated in the air spheres (Fig. S8).

In our sandwich-structured PC design, the top and bottom layers serve as a set of mirrors for transmitted (through top layer) and rejected (by bottom layer) light to circulate in the middle layer, which could tremendously increase the light path length, enhancing light absorption. A much-simplified analogy of this phenomenon is multiple beam interference which leads to photon circulation. ${ }^{60-63}$ However, the light manipulation involved in the $\mathrm{S}-\mathrm{IO}-\mathrm{TiO}_{2}$ is much more complex: although the mirror effect of inverse opals is wavelength-specific, the scattering at interfaces between the different layers is of broad spectrum; In addition to functioning as the 'resonance cavity', the middle layer itself is a $\mathrm{TiO}_{2} \mathrm{IO}$ with stopband position tuned to generate slow photons at $\mathrm{TiO}_{2}$ electronic bandgap edge. Therefore, the slow photons are further slowed since they are forced to pass through the PC that slows them down a few to many times, which enhances the light absorbance tremendously, as demonstrated in this study. Though the overall structure falls in the category of FabryPérot micro-resonator, the sandwich-structured PC as described is unconventional, owing to the unique design of the stopband spectral positions, which maximizes the generation and utilization of slow photons at the absorption edge of the material.

It should also be appreciated that slowing down electronhole recombination is critical to photocatalytic reaction efficiency so that the photo-generated free electrons and the holes can be effectively utilized. Extension of their recombination time is usually achieved by introducing another material for facilitating electron transport. It is surprising that by adopting the sandwich-structured, the $\mathrm{S}-\mathrm{IO}-\mathrm{TiO}_{2}$ can extend the electron-hole recombination time by 2 -fold in comparison to its monolithic counterpart, purely based on photon management. This may be understood by the photon circulation effect as shown in Fig. 3b; the trapped light in the middle layer of the sandwich-structured continuously excites the $\mathrm{TiO}_{2}$ and sustains the electron-hole separation.

\section{Conclusions}

In summary, we have designed a novel PC structure for photoactive semiconductors to maximize photon absorbance at the electronic absorption edge. The sandwich-structured PC is comprised of a top and bottom PC layer with a bandgap whose blue (or red) edge overlapping with the electronic excitation energy of the semiconductor, and the middle PC layer with a bandgap whose red (or blue) edge tuned in the same manner. Such a microcavity construct is able to trap the slow photons in the middle PC layer, maximizing light absorbance. In comparison to its monolithic counterpart, this 
new structural configuration has resulted in more than 4-fold yield in photocurrent density in the PEC application, 6-fold faster photocatalytic kinetics, and more than twice as long electron-hole recombination time. Such a rational design for maximizing slow photon utilization and further slowing down slow photons may have a profound impact on light harvesting, optoelectronics, photochemical reactions and photo-active materials in general.

\section{Acknowledgements}

The authors acknowledge the support from the Australia Research Council (ARC) under the Project DP160104089, and appreciate the access to the electron microscopes at the Centre for Microscopy and Microanalysis at the University of Queensland.

\section{Notes and references}

¥ Monolithic $\mathrm{TiO}_{2}$ inverse opal whose red (blue) edge of stopband is in tune with $\mathrm{TiO}_{2}$ electronic bandgap edge is denoted as M-IO-R (M-IO-B). Heterostructure and sandwichstructured $\mathrm{TiO}_{2}$ inverse opal that both red and blue edges of stopbands are in tune with $\mathrm{TiO}_{2}$ electronic excitation energy are denoted as $\mathrm{H}-\mathrm{IO}-\mathrm{TiO}_{2}$ and $\mathrm{S}-\mathrm{IO}-\mathrm{TiO}_{2}$.

$\S$

$\S \S$

1. X. Zheng and L. Zhang, Energy \& Environmental Science, 2016, DOI: 10.1039/C6EE01182A.

2. J. Zhu, Z. Yu, S. Fan and Y. Cui, Materials Science and Engineering: R: Reports, 2010, 70, 330-340.

3. X. B. Chen, L. Liu, P. Y. Yu and S. S. Mao, Science, 2011, 331, 746-750.

4. F. Ning, M. Shao, S. Xu, Y. Fu, R. Zhang, M. Wei, D. G. Evans and X. Duan, Energy \& Environmental Science, 2016, DOI: 10.1039/C6EE01092J.

5. W. Zhou, W. Li, J. Q. Wang, Y. Qu, Y. Yang, Y. Xie, K. F. Zhang, L. Wang, H. G. Fu and D. Y. Zhao, J. Am. Chem. Soc., 2014, 136, 9280-9283.

6. D. Chen, F. Huang, Y.-B. Cheng and R. A. Caruso, Advanced Materials, 2009, 21, 2206-+.

7. W. R. Erwin, H. F. Zarick, E. M. Talbert and R. Bardhan, Energy \& Environmental Science, 2016, 9, 1577-1601.

8. Y.-R. Lu, P.-F. Yin, J. Mao, M.-J. Ning, Y.-Z. Zhou, C.-K. Dong, T. Ling and X.-W. Du, Journal of Materials Chemistry A, 2015, 3, 18521-18527.

9. X.-L. Zheng, J.-P. Song, T. Ling, Z. P. Hu, P.-F. Yin, K. Davey, X.-W. Du and S.-Z. Qiao, Advanced Materials, 2016, 28, 4935-4942.

10. A. Stein, B. E. Wilson and S. G. Rudisill, Chemical Society Reviews, 2013, 42, 2763-2803.

11. E. Yablonovitch, Physical Review Letters, 1987, 58, 20592062.

12. L. Liu, S. K. Karuturi, L. T. Su and A. I. Y. Tok, Energy \& Environmental Science, 2011, 4, 209-215.

13. L. T. Su, S. K. Karuturi, J. Luo, L. Liu, X. Liu, J. Guo, T. C. Sum, R. Deng, H. J. Fan, X. Liu and A. I. Y. Tok, Advanced Materials, 2013, 25, 1603-1607.

14. H. Zhao, M. Wu, J. Liu, Z. Deng, Y. Li and B.-L. Su, Applied Catalysis B: Environmental, 2016, 184, 182-190.
15. E. S. Kwak, W. Lee, N.-G. Park, J. Kim and H. Lee, Advanced Functional Materials, 2009, 19, 1093-1099.

16. M. Wu, J. Liu, J. Jin, C. Wang, S. Huang, Z. Deng, Y. Li and B.-L. Su, Applied Catalysis B: Environmental, 2014, 150151, 411-420.

17. M. Zalfani, B. van der Schueren, Z.-Y. Hu, J. C. Rooke, R. Bourguiga, M. Wu, Y. Li, G. Van Tendeloo and B.-L. Su, Journal of Materials Chemistry A, 2015, 3, 21244-21256.

18. K. R. Phillips, G. T. England, S. Sunny, E. Shirman, T. Shirman, N. Vogel and J. Aizenberg, Chemical Society Reviews, 2016, 45, 281-322.

19. J. Liu, J. Jin, Y. Li, H.-W. Huang, C. Wang, M. Wu, L.-H. Chen and B.-L. Su, Journal of Materials Chemistry A, 2014, 2, 5051-5059.

20. J. Liu, H. Zhao, M. Wu, B. Van der Schueren, Y. Li, O. Deparis, J. Ye, G. A. Ozin, T. Hasan and B.-L. Su, Advanced Materials, 2017, DOI: 10.1002/adma.201605349, 1605349-n/a.

21. S. Nishimura, N. Abrams, B. A. Lewis, L. I. Halaoui, T. E. Mallouk, K. D. Benkstein, J. van de Lagemaat and A. J. Frank, J. Am. Chem. Soc., 2003, 125, 6306-6310.

22. J. I. L. Chen, G. von Freymann, S. Y. Choi, V. Kitaev and G. A. Ozin, Advanced Materials, 2006, 18, 1915-+.

23. J. I. L. Chen, G. von Freymann, S. Y. Choi, V. Kitaev and G. A. Ozin, Journal of Materials Chemistry, 2008, 18, 369373.

$24 . \quad J$. I. L. Chen and G. A. Ozin, Journal of Materials Chemistry, 2009, 19, 2675-2678.

25. H. Li, J. Wang, H. Lin, L. Xu, W. Xu, R. Wang, Y. Song and D. Zhu, Advanced Materials, 2010, 22, 1237-1241.

26. M. Wu, J. Jin, J. Liu, Z. Deng, Y. Li, O. Deparis and B.-L. Su, Journal of Materials Chemistry A, 2013, 1, 15491-15500.

27. M. Curti, J. Schneider, D. W. Bahnemann and C. B. Mendive, The Journal of Physical Chemistry Letters, 2015, 6, 3903-3910.

28. Y. Yang, Q. Jin, D. Mao, J. Qi, Y. Wei, R. Yu, A. Li, S. Li, H. Zhao, Y. Ma, L. Wang, W. Hu and D. Wang, Advanced Materials, 2017, 29, 1604795-n/a.

29. S. Shuang, R. Lv, Z. Xie and Z. Zhang, Scientific Reports, 2016, 6, 26670.

30. J. Schneider, M. Matsuoka, M. Takeuchi, J. Zhang, Y. Horiuchi, M. Anpo and D. W. Bahnemann, Chemical Reviews, 2014, 114, 9919-9986.

31. T. Ling, S. A. Kulinich, Z.-L. Zhu, S.-Z. Qiao and X.-W. Du, Advanced Functional Materials, 2014, 24, 707-715.

32. M. Zalfani, B. van der Schueren, M. Mahdouani, R. Bourguiga, W.-B. Yu, M. Wu, O. Deparis, Y. Li and B.-L. Su, Applied Catalysis B: Environmental, 2016, 199, 187-198.

33. Q. Li. and E. Eftekhari., in Nanostructures: Properties, Production Methods and Applications, ed. Y. Dong, Nova Science Publishers, 2013, ch. 4, pp. 169-183.

34. Q. Li, M. Askildsen and E. Eftekhari, in Design of Polymeric Platforms for Selective Biorecognition, eds. J. RodríguezHernández and L. A. Cortajarena, Springer International Publishing, Cham, 2015, DOI: 10.1007/978-3-319-170619_12, pp. 325-346.

35. Z. Zhou, Q. Yan, Q. Li and X. S. Zhao, Langmuir, 2007, 23, 1473-1477.

36. C. Zhou, J. Han and R. Guo, Journal of Colloid and Interface Science, 2013, 397, 80-87.

37. E. Eftekhari, I. S. Cole and Q. Li, Physical Chemistry Chemical Physics, 2016, 18, 1743-1749. 

Minggu and M. H. S. Ismail, Applied Surface Science, 2014, 289, 53-61.

39. S.-J. Ha, D. H. Kim and J. H. Moon, RSC Advances, 2015, 5, 77716-77722.

40. T. K. Rahul and N. Sandhyarani, Nanoscale, 2015, 7, 18259-18270.

41. A. Memar, W. R. W. Daud, S. Hosseini, E. Eftekhari and L. J. Minggu, Solar Energy, 2010, 84, 1538-1544.

42. S. Hosseini, E. Eftekhari, S. Masoudi Soltani, A. Memar, F. Eghbali Babadi, B. Dastorian Jamnani, M. H. S. Ismail and L. Jeffery Minggu, Journal of Environmental Chemical Engineering, 2013, 1, 1309-1314.

43. X. Chen, J. Ye, S. Ouyang, T. Kako, Z. Li and Z. Zou, ACS Nano, 2011, 5, 4310-4318.

44. X. Shi, K. Zhang and J. H. Park, International Journal of Hydrogen Energy, 2013, 38, 12725-12732.

45. N. J. Bell, Y. H. Ng, A. Du, H. Coster, S. C. Smith and R. Amal, The Journal of Physical Chemistry C, 2011, 115, 6004-6009.

46. Optiwave, Academic, 2008, 3-8.

47. S. Guo and S. Albin, Optics Express, 2003, 11, 167-175.

48. Q. F. Yan, Z. C. Zhou and X. S. Zhao, Langmuir, 2005, 21, 3158-3164.

49. P. Jiang, J. F. Bertone, K. S. Hwang and V. L. Colvin, Chemistry of Materials, 1999, 11, 2132-2140.

50. J. Lin, Y.-U. Heo, A. Nattestad, Z. Sun, L. Wang, J. H. Kim and S. X. Dou, Scientific Reports, 2014, 4, 5769.

51. Z. Cai, J. Teng, Z. Xiong, Y. Li, Q. Li, X. Lu and X. S. Zhao, Langmuir, 2011, 27, 5157-5164.

52. J. I. L. Chen, G. von Freymann, S. Y. Choi, V. Kitaev and G. A. Ozin, Advanced Materials, 2006, 18, 1915-1919.

53. C. Cheng, S. K. Karuturi, L. Liu, J. Liu, H. Li, L. T. Su, A. I. Y. Tok and H. J. Fan, Small, 2012, 8, 37-42.

54. K. Kim, P. Thiyagarajan, H.-J. Ahn, S.-I. Kim and J.-H. Jang, Nanoscale, 2013, 5, 6254-6260.

55. Y. Wei, J. Jiao, Z. Zhao, W. Zhong, J. Li, J. Liu, G. Jiang and A. Duan, Journal of Materials Chemistry A, 2015, 3, 1107411085.

56. Z. Zhang, X. Yang, M. N. Hedhili, E. Ahmed, L. Shi and P. Wang, ACS Appl. Mater. Interfaces, 2014, 6, 691-696.

57. L. N. Quan, Y. H. Jang, K. A. Stoerzinger, K. J. May, Y. J. Jang, S. T. Kochuveedu, Y. Shao-Horn and D. H. Kim, Physical Chemistry Chemical Physics, 2014, 16, 9023-9030.

58. A. Hagfeldt, H. Lindström, S. Södergren and S.-E. Lindquist, Journal of Electroanalytical Chemistry, 1995, 381, 39-46.

59. O. Deparis, S. R. Mouchet and B. L. Su, Physical Chemistry Chemical Physics, 2015, 17, 30525-30532.

60. E. Eftekhari, X. Li, T. H. Kim, Z. Gan, I. S. Cole, D. Zhao, D. Kielpinski, M. Gu and Q. Li, Scientific Reports, 2015, 5, 14439.

61. E. Yablonovitch, Science, 2016, 351, 1401-1401.

62. L. M. Pazos-Outón, M. Szumilo, R. Lamboll, J. M. Richter, M. Crespo-Quesada, M. Abdi-Jalebi, H. J. Beeson, M. Vrućinić, M. Alsari, H. J. Snaith, B. Ehrler, R. H. Friend and F. Deschler, Science, 2016, 351, 1430-1433.

63. E. Eftekhari, W. Wang, X. Li, N. A, Z. Wu, R. Klein, I. S. Cole and Q. Li, Sensors and Actuators B: Chemical, 2017, 240, 204-211. 